\title{
Donor odor: The presence or absence as a mediator of behavior in the runway-trained rat
}

\author{
ROBERT E. PRYTULA \\ Middle Tennessee State University, Murfeesboro, Tennessee 37132 \\ STEPHEN F. DAVIS \\ Austin, Peay State University, Clarksville, Tennessee 37040 \\ and \\ JOHN FITE \\ Middle Tennessee State University, Murfeesboro, Tennessee 37132
}

\begin{abstract}
In two four-phase experiments, a double-alternation sequence of goal events, and hence odors, of donor rats was initially presented to runway-trained rats (experimental animals) in the startbox of a runway. Following this phase, the odors from the donor rats were selectively removed, reinstated, and removed again. Although the performance of the experimental animals was substantially controlled by the odors emitted by the donor rats, it was found that appropriate responding could be maintained in the start measure when donor cues were removed from the startbox.
\end{abstract}

Previous demonstrations by Ludvigson and Sytsma (1967), Seago, Ludvigson, and Remley (1970), and others have shown that the reinforcement events experienced by any one rat can affect the performance of subsequent animals. This has been particularly evident when rats are exposed to an alternating schedule of reward and nonreward, for example, a single-alternation schedule (Amsel, Hug, \& Surridge, 1969) or doublealternation schedule (Seago et al., 1970). Specifically, when rats are administered a double-alternation schedule of reward and nonreward, responding in the goal section of a runway is mediated by odor cues from previously run animals. Animals run under these schedules run fast on the rewarded trials and slow on the nonrewarded trials, hence their behavior tracks the schedule (i.e., pattern responding). The basis of these odor cues appears to be that rats exude a distinctive odor on the $\mathrm{N}$ trials of a reinforcement schedule (Morrison \& Ludvigson, 1970). Furthermore, release of these odors appears to be an emotional response that is associated with nonreward.

Through the use of a donor technique, similar pattern responding has been selectively established in the start and run sections of the runway (Davis, Prytula, Harper, Tucker, Lewis, \& Flood, 1974; Davis, Prytula, Noble, \& Mollenhour, 1976; Prytula \& Davis, 1974, 1976). This procedure involves the direct placement of a donor rat, and hence odor cue, into a designated section of

This research was supported by a faculty research grant from Middle Tennessee State University to the first author, and a Tower Fund research grant from Austin Peay State University to the second author. the runway, the start area or middle of the run section. The donor rat experiences a reward or nonreward event at this location and is then removed from the apparatus. A runway-trained experimental animal is immediately placed in the start area and allowed to traverse the entire runway, with the effect and influence of the donor's odor confined to the start or run section.

As indicated in our previous research (Davis et al., 1974; Prytula \& Davis, 1974, 1976), odor cues produced by the donor animals must be predictive and redundant of the experimental animal's goal events in order for pattern responding to be obtained in the start and run sections of the runway. Shifting the donor animal's schedule to anything less than perfect correspondence with that experienced by the experimental animals has consistently resulted in a pronounced and lasting disruption in the experimental animal's patterning in the start and run measures. It should be noted that previous demonstrations by Ludvigson and Sytsma (1967) and Seago et al. (1970), not using donor animals, have shown that patterning is limited to the goal area. In light of these findings, it seems worthwhile to establish the generality of these results using other sequences of donor-cue presentation. Specifically, donor cues were manipulated by alternately establishing and removing these cues in the start area and assessing whether pattern responding by experimental animals would be maintained in the absence of these cues.

\section{EXPERIMENT 1}

\section{Method}

Subjects. Twenty-eight naive male albino rats, approximately 90 days old at the beginning of the experiment, were purchased 
from the Holtzman Company, Madison, Wisconsin, and served as subjects. Ten days prior to pretraining, the subjects were placed on an $85 \%$ ad-lib body-weight deprivation schedule. Maintenance of the deprivation schedule, which continued for the duration of the experiment, took place following the daily experimental session. Subjects were housed in individual cages with water freely available.

Apparatus. The apparatus consisted of a single straight runway ( $16.51 \mathrm{~cm}$ high $\times 9.16 \mathrm{~cm}$ wide $\times 152.4 \mathrm{~cm}$ long) divided into start, run, and goal sections. The entire runway was covered with hinged Plexiglas covers. Start, run, and goal latencies were recorded on all trials after the interruption of a series of photoelectric cells and a microswitch located on the start door. The start photocell was located $.21 \mathrm{~m}$ from the start door; the run photocell was located .61 from the start photocell; and the goal photocell was located $.31 \mathrm{~m}$ from the run photocell. The goal cup was located on the end wall of the goalbox.

Guillotine doors separated the start and goal areas from the run segment of the runway. The start door was made of frosted Plexiglas, and the goal door was made of clear Plexiglas. The doors prevented subjects from retracing once a photocell had been interrupted.

Procedure. At the beginning of the 4-day pretraining phase, rats were randomly assigned to two equal groups: donor and experimental groups. Each rat was assigned a permanent number (1-14) within its respective group. During pretraining, all rats were handled and tamed on the first 2 days. On Days 3 and 4 of pretraining, the experimental animals received a 5-min exploration period in the apparatus. On these days, the donor animals received a comparable amount of handling. All animals received daily pellet habitation to the $300-\mathrm{mg}$ Noyes reward pellets in the home cage during pretraining.

Animals were further divided into two additional groups immediately prior to the experiment. Group 1, consisting of donor and experimental Animals 1-7, received all daily experimental trials immediately before the trials of Group 2 (donor and experimental Animals 8-14).

Each animal was run on an eight-trial double-alternation schedule (RRNNRRNN). All animals within a group received Trial 1 before Trial 2 was begun, and so on. The procedure for running a trial during Phases 1 and 3 was to place the appropriate donor (i.e., donor Rat 1 was used when experimental Rat 1 was to be run, etc.) directly into the startbox. As soon as the reward (two $300-\mathrm{mg}$ pellets) was consumed or a $30-\mathrm{sec}$ nonreward confinement period elapsed, the donor was removed from the startbox and the experimental rat placed there. Following a 10-sec confinement period, the experimental animal was allowed to traverse the runway. During Phases 2 and 4, procedures were identical, with the exception that the donor animals received placements in an adjacent operant box instead of the startbox of the runway. Thus, donor cues were present in the startbox during Phases 1 and 3 , and absent during Phases 2 and 4. Phase 1 lasted 14 days (112 trials); Phases 2-4 were each 5 days (40 trials) long.

\section{Results}

Start, run, and goal times were reciprocated and multiplied by the approriate constants to yield a speed in meters per second. ${ }^{1}$ For purposes of analysis and graphical presentation, the speed scores were averaged as follows: Trials 1-2 were averaged to yield an $R_{1}$ composite, Trials 3-4 were averaged to yield an $\mathrm{N}_{1}$ composite, and so forth. An R-N by days by subjects ANOVA was performed on the speed data. Group mean speeds (meters/second) for the four phases of Experiment 1 are shown in Figure 1. Before discussing various results, it should be noted that very little between-subjects variability was observed; hence, the group curves are quite representative of individual subjects.

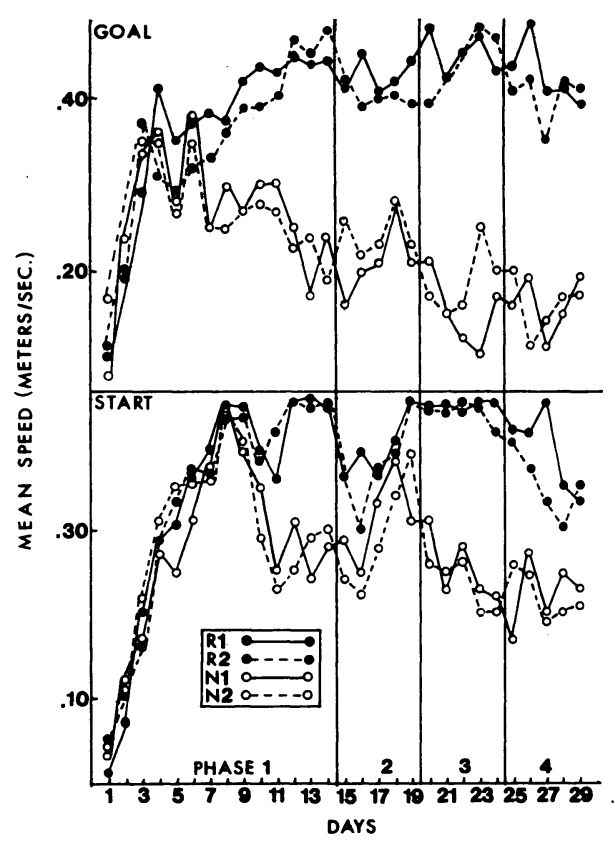

Figure 1. Mean start and goal speeds, Experiment 1.

Phase 1. Analysis performed over Days 10-14 (the point at which double-alternation patterning had developed in all segments) indicated that the $R$ vs. $N$ effect was significant in all measures [start, $F(3,33)=$ $10.98, \mathrm{p}<.001$; run, $\mathrm{F}(3,33)=10.46, \mathrm{p}<.001$; goal, $F(3,33)=27.84, p<.001]$. Also, the $R-N$ by Days interaction was found to be significant in all three measures [start, $\mathrm{F}(12,132)=3.10, \mathrm{p}<.001$; run, $F(12,132)=2.22, p<.005$; goal, $F(12,132)=3.21$, $p<.001]$. Simple effects analysis indicated that $R_{1}$ and $R_{2}$ were significantly faster $\left(R_{1}, p<.05 ; R_{2}\right.$, $p<.01)$ than both $N_{1}$ and $N_{2}$ in all three segments.

Phase 2. Significant $R$ vs. $N$ effects were found in all three measures [start, $F(3,33)=5.54, p<.005$; run, $F(3,33)=8.71, p<.001$; goal, $F(3,33)=37.61$, $p<.001]$. Simple effects analysis indicated that $R_{1}$ and $R_{2}$ were significantly faster than $N_{1}(p<.01)$ and $N_{2}$ $(\mathrm{p}<.05)$ in all segments. Also, a significant $[F(4,44)=$ $3.77, p<.05]$ days effect was shown in the start measure.

Phase 3. Again, the R vs. N effect was found to be significant in all measures [start, $F(3,33)=22.78, p<.001$; run, $F(3,33)=17.53, p<.001$; goal, $F(3,33)=78.66$, $\mathrm{p}<.001]$. Simple effects analysis indicated that both $R_{1}$ and $R_{2}$ were significantly faster $(p<.001)$ than $N_{1}$ and $\mathrm{N}_{2}$ in all measures. A significant days effect was found in the run measure $[F(4,44)=2.76, p<.01]$.

Phase 4. As in Phases 1-3, the $R$ vs. $N$ effect was significant in all measures [start, $F(3,33)=9.03, p<.001$; run, $F(3,33)=33.15, p<.001$; goal, $F(3,33)=63.51$, $p<.001]$. Simple effects analysis indicated that $R_{1}$ and $R_{2}$ were both significantly $(p<.001)$ faster than $\mathrm{N}_{1}$ and $\mathrm{N}_{2}$ in all measures.

\section{Discussion}

When compared to our previous data, the present results indicate that simply removing and reinstating an odor cue (see 
Figure 1, Phases 2 and 4) does not have as dramatic an effect as negatively correlating the donor and experimental animals' schedules (see Prytula \& Davis, 1976). There is a loss of strength in patterning in the start measure during Phase 2, but patterning in the goal remained virtually unchanged. Start-measure patterning was quickly reestablished in Phase 3 (donors once again present), and, surprisingly, remained quite strong when the donors were once again removed (Phase 4). Of course, it could be suggested that the subjects were simply attending to some other external cue during Phases 2 and 4, and this served to maintain patterning. An examination of Figure 2, which shows the speeds of Subjects 1 and 8 , the first subject of each group, indicates that this was not the case, as these subjects failed to display patterning during any phase. It would appear that once double-alternation patterning has been established via predictable odor cues, it can be maintained in the absence of these cues as long as the cue predictability is not disrupted.

\section{EXPERIMENT 2}

The results of Experiment 1 were quite surprising in that the experimental animals appeared quite capable of responding in absence of the donor animals' odor, especially during Phase 4 . There are several possible explanations as to why patterning was maintained in absence of odor cues: (1) Odor cues might in some way interact with memory, allowing retrieval in their absence; (2) the experimental animals were selectively utilizing other external cues such as teeth chattering, ultrasonic communication, and/or chewing of residual food on the reward trials provided in the animal colony by previously run subjects; and (3) removal and reinstatement of donor odor sensitized the experimental animals during Phase 4 such that they were then able to utilize goalbox odors that disseminated (albeit weakly) throughout the runway.

Experiment 2 represents a four-phase replication of

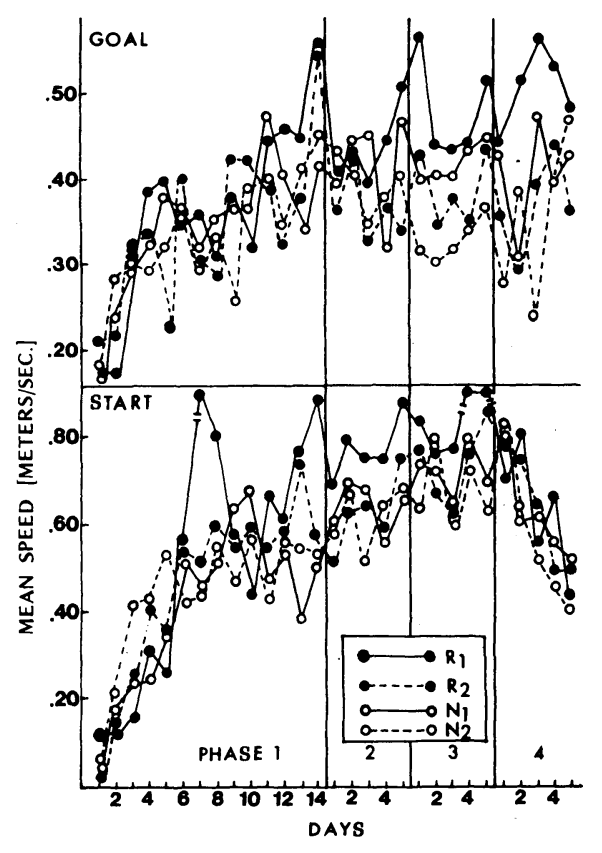

Figure 2. Mean start and goal speeds for Subjects 1 and 8 , Experiment 1.
Experiment 1 with an additional intervention during Phase 3. During this phase, the donor animals were reinforced in a neutral box following selected nonrewarded trials in the startbox. Thus, on these trials, any "message," other than startbox odors, that was communicated by donors to subsequent experimental animals inaccurately signaled reward.

\section{Method}

Subjects. Twenty-four naive male albino rats, approximately 90 days old at the onset of the experiment, were purchased from the Holtzman Company, Madison, Wisconsin, and served as subjects. Deprivation and housing conditions identical to those of Experiment 1 were employed.

Apparatus. The apparatus utilized in Experiment 2 consisted of a single straight runway $(11.43 \mathrm{~cm}$ wide, $12.70 \mathrm{~cm}$ high). A gray startbox ( $28.10 \mathrm{~cm}$ long) was separated by a Masonite guillotine door from the rest of the runway. The raising of this door served to activate, via a microswitch, a Standard electric timer. Breaking a photoelectric beam located $15.24 \mathrm{~cm}$ beyond the start door stopped the first timer (start time) and started a second timer. Breaking a second beam located $76.20 \mathrm{~cm}$ beyond the first beam stopped the second timer (run time) and started the third timer. The third timer was stopped by breaking a third photoelectric beam located $5.08 \mathrm{~cm}$ forward of the goal cup. A small plastic receptacle recessed into the end wall of the goalbox served as the goal cup. The top of the runway was covered by a thin sheet of plastic to prevent the dissipation of odors.

Procedure. Prior to the onset of a 4-day pretraining period, all rats were randomly assigned to one of two equal groups: donor and experimental. Further, each animal was assigned a permanent number (1-12) within its respective group. On Days 1 and 2 of pretraining, all animals were handled and tamed. On Days 3 and 4, each experimental rat received a $5-\mathrm{min}$ period of exploration in the unbaited apparatus. Donor animals received an equal amount of handling on those days. On the 4 pretraining days, all animals were habituated to the $45-\mathrm{mg}$ Noyes pellets in the home cage.

Each rat received eight trials: four reward (R) and four nonreward $(N)$ in a double-alternation pattern (RRNNRRNN) throughout all four phases of the experiment. All rats received Trial 1 before Trial 2, and so forth. The order of running the animals was randomized daily. For each trial, the appropriate donor was selected for use with the experimental animal; that is, Donor 1 was used with experimental Animal 1, and so on.

During Phase 1, the procedure for running a trial was as follows: The donor was removed from the home cage and placed directly into the startbox. On reward trials, each animal was removed following the consumption of the reward (12 45-mg Noyes pellets). On nonreward trials, each animal was removed after being confined for $30 \mathrm{sec}$. Following this, the experimental rat was immediately placed into the startbox and confined for a 10 -sec period, and then allowed to traverse the runway. Phase 1 lasted 14 days (112 trials).

Phase 2 differed from Phase 1 in that the donor animals received the usual pattern of reward and nonreward in a neutral box. At no time during Phase 2 were the donor animals in the startbox of the runway. Experimental animals, on the other hand, received treatment identical to that of Phase 1.

Phase 3 was identical to Phase 1 with the following exceptions: Following the first two nonreward trials on Days 1-3, each donor animal was placed into the neutral box outside the runway, and reward was administered. On Days 4-6, reward was administered in the neutral box following the last two nonreward trials. These condjtions were imposed in order to evaluate the possibility of communication between donors and the remainder of the colony by some means other than odor (e.g., gnashing of teeth or ultrasound).

During Phase 4 , conditions were again identical to those employed in Phase 2. Phases 2-4 were each 6 days (48 trials) in duration. 


\section{Results}

Start, run, and goal times were reciprocated and multiplied by the appropriate constant to yield speed scores in meters per second. Figure 3 shows the mean start and goal speeds for Days 8-14 of Phase 1 (the point at which double-alternation patterning had developed). and Phases 2-4. An R-N by days by subjects ANOVA was performed on these data. Speeds $\left(R_{1}, N_{1}\right.$, $\mathbf{R}_{2}, \mathrm{~N}_{2}$ ) were calculated as in Experiment 1 . The results of these analyses are considered separately for each phase.

Phase 1. Analysis performed on the data from Days 814 indicated that the $\mathrm{R}$ vs. $\mathrm{N}$ effect was significant in the start $[F(1,143)=4.26, p<.05]$ and goal $[F(1,143)=$ $5.07, \mathrm{p}<.05]$ measures. Thus, the statistical analyses corroborate the graphical impression (see Figure 3) that significant double-alternation patterning developed in the start and goal measures during Phase 1.

Phase 2. Goal-speed analyses yielded a significant $R$ vs. $\mathrm{N}$ effect $[\mathrm{F}(1,121)=7.21, \mathrm{p}<.01]$, and the $\mathrm{R}-\mathrm{N}$ by Days interaction was found to be significant $[F(5,121)=$ $4.82, \mathrm{p}<.05$ ] in the start measure. Further inspection of the significant start-measure interaction (Tukey's procedure) indicated that significant $(\mathrm{p}<.05) \mathrm{R}$ vs. $\mathrm{N}$ differences existed only, on Days 5 and 6.

Phase 3. Significant $R$ vs. $N$ effects were shown in Phase 3 in both the start $[F(1,121)=8.86, p<.01]$, and goal $[F(1,121)=9.65, p<.01]$ measures. No other significant effects were produced by analyses of this phase.

Phase 4. Phase 4 results mirrored those of Phase 3 in that significant $\mathrm{R}$ vs. $\mathrm{N}$ effects were obtained in both the start $[F(1,121)=4.02, p<.05]$ and goal $[F(1,121)=$ $11.52, p<.01]$ measures. As in Phase 3 , these were the only significant effects produced by the analyses.

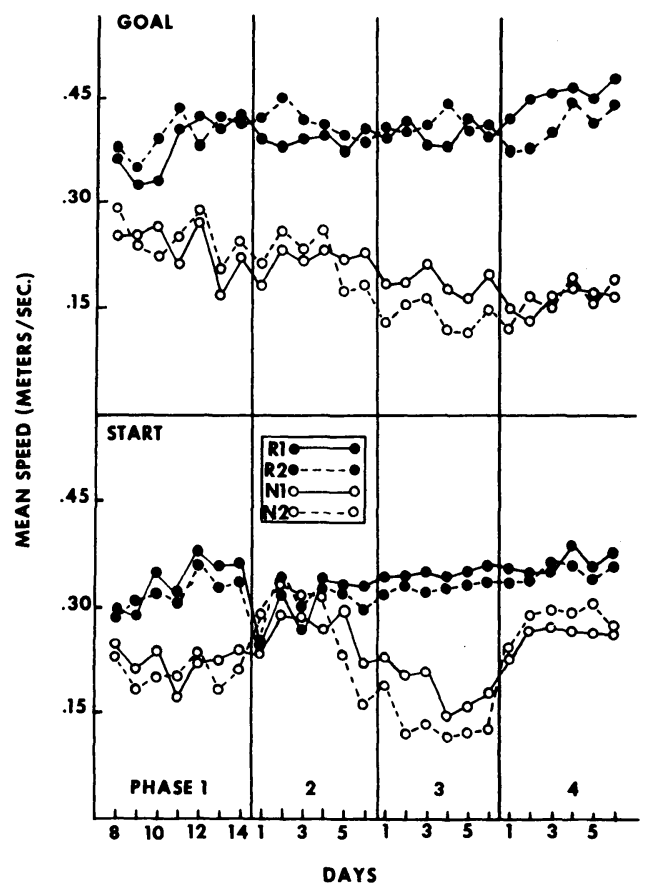

Figure 3. Mean start and goal speeds, Experiment 2.

\section{Discussion}

As in Experiment 1, double-alternation responding developed in Phase 1 in both the start and goal measures; when the donor animals were removed as in Phase 2 , there was a pronounced disruption in the start-measure performance. Goal performance remained unaffected. Reintroduction of the donor animals in Phase 3 led to an immediate reinstatement of start-measure responding. Removal of the donor animals in Phase 4 , as in Experiment 1, produced a slight disruption; however, pattern responding was clearly maintained, albeit reduced.

Interpolated feeding of donor animals in the neutral box following selected nonrewarded trials during Phase 3 had absolutely no effect upon the performance of the experimental animals. If some form of communication other than odors had taken place, a change in the response pattern of the experimental animals should have been detected. The experimental animals' performance continued to be under the control of odors left by the donor animals on the $\mathrm{N}$ trials. It would appear that these cues are apparatus based and not communicated to subsequent experimental animals outside the apparatus confines (e.g., in the animal colony). At present, the most likely candidate would appear to be odors disseminating from the goalbox, thereby sensitizing the experimental animals to these odors.

\section{GENERAL DISCUSSION}

Previous research (Davis et al., 1976; Prytula \& Davis, 1974, 1976), in conjunction with the present studies, shows that rats readily utilize odor cues and regulate their runway behavior according to these events. In all of our research, the experimental animals have received a double-alternation schedule of reward and nonreward that was unchanged throughout the course of these experiments. However, when the reinforcement schedule, hence odor, of donor rats was changed, this produced pronounced behavioral changes in the experimental animals.

\section{REFERENCES}

Amsel, A., Hug, J. J., \& Surridge, C. T. Subject to subject trial sequence, odor trials, and patterning at 24-h ITI. Psychonomic Science, 1969, 15, 787-793.

Davis, S. F., Prytula, R. E., Harper, W. E., Tucker, H. K., LEwIS, C., \& FlOod, L. Double-alternation runway performance as a function of inter- and intra-reinforcement odor cues. Psychological Reports, 1974, 35, 787-793.

Davis, S. F., Prytula, R. E., Noble, M. J., \& Mollenhour, M. N. Motivational specificity of the signal value of odor cues. Animal Learning \& Behavior, 1976, 4, 407-410.

Ludvigson, H. W., \& Sytsma, D. The sweet smell of success: Apparent double alternation in the rat. Psychonomic Science, 1967, 9, 282-284.

MorRison, R. R., \& Ludvigson, H. W. Discrimination by rats of conspecific odors of reward and nonreward. Science, 1970, 167, 904-905.

Prytula, R. E., \& Davis, S. F. Runway performance as a function of positively and negatively correlated olfactory cues. Psychological Reports, 1974, 35, 735-740.

Prytula, R. E., \& Davis, S. F. The relationship between locus of odor cues and double-alternation responding in the rat. Animal Learning \& Behavior, 1976, 4, 352-356.

Seago, J. D., Ludvigson, H. W., \& Remley, N. R. Effects of anosmia on apparent double-alternation in the rat. Journal of Comparative and Physiological Psychology, 1970, 71, 435-442.

\section{NOTE}

1. Since Rats 1 and 8 were the first rats run in a squad, they were essentially "donor" rats for subsequently run animals in the goal segment. Their data were not included in the analyses. 